\title{
Improving health data for indigenous populations: The international group for indigenous health measurement
}

\author{
Michelle Chino ${ }^{\mathrm{a}, *}$, Ian Ring ${ }^{\mathrm{b}}$, Lisa Jackson Pulver ${ }^{\mathrm{c}}$, John Waldon ${ }^{\mathrm{d}}$ and Malcolm King ${ }^{\mathrm{e}}$ \\ ${ }^{a}$ School of Community Health Sciences, University of Nevada Las Vegas, Las Vegas, NV, USA \\ ${ }^{\mathrm{b}}$ Research and Innovation Division, University of Wollongong, Wollongong, Australia \\ ${ }^{\mathrm{c}}$ Indigenous Strategy and Services, The University of Sydney, Sydney, Australia \\ ${ }^{\mathrm{d}}$ School of Public Health and Community Medicine, UNSW Sydney, Sydney, Australia \\ ${ }^{\mathrm{e}}$ Department of Community Health and Epidemiology, University of Saskatchewan, Saskatoon, SK, Canada
}

\begin{abstract}
Health disparities between Indigenous and non-Indigenous populations exist in many countries, including those with well-developed statistical systems. The need to improve the measurement and understanding of Indigenous health disparities led to the formation of the International Group for Indigenous Health Measurement (IGIHM), composed of Indigenous and non-Indigenous, government and non-government, statisticians, researchers and health professionals. Since its founding in 2005 , the IGIHM has pursued activities to improve health measurement, which in turn have been used for improving the health of Indigenous populations and enhancing Indigenous health knowledge and data.
\end{abstract}

Keywords: Indigenous people, Indigenous health measurement, multinational interest group, health disparities, challenges for Indigenous health measurement

\section{Introduction}

Health disparities between Indigenous and nonIndigenous populations exist in many countries, but have been best described in countries with welldeveloped statistical systems. This includes the four founding members of this group: Australia, Canada, New Zealand, and the United States. All four countries have identified Indigenous health disparities as important to address as we seek to improve the measurement and understanding of Indigenous health status. This challenge, along with a common language and common colonial experience, led a disparate group of individuals from the four countries to form an international interest group to promote improvement in the measure-

${ }^{*}$ Corresponding author: Michelle Chino, School of Community Health Sciences, University of Nevada Las Vegas, USA. E-mail: michelle.chino@unlv.edu. ment of Indigenous health status. This group is known as the International Group for Indigenous Health Measurement (IGIHM).

Data and health statistics are essential to identifying and monitoring disparities, measuring change between populations within and between countries, and ultimately to reducing health burdens. But if the goal of health equity is to be achieved, data are needed to demonstrate that these disparities are not just thirdworld problems, and that significantly poorer health outcomes exist for Indigenous peoples in advantaged countries such as Australia, Canada, New Zealand and the United States [1]. Unfortunately, the accuracy and completeness of health data for Indigenous populations in these countries are poor, as are data on the driving social, economic, cultural and political factors.

The IGIHM was founded in 2005 and brings together a diverse set of people, Indigenous and nonIndigenous, government and non-government, statisti- 
cians, researchers and health professionals. The IGIHM's stated goals are first, to promote awareness of the deficiencies of health data for Indigenous populations in our four countries and second, to collaborate internationally on improved methods and policies that will contribute to the improvement of Indigenous health. Since its founding in 2005, the IGIHM has pursued a variety of activities to further its stated goals. These activities have centered on multi-national partnerships as well as the promotion of improved methods for the collection, analysis, interpretation and dissemination of information useful for improving the health of Indigenous populations, enhancing Indigenous health knowledge and data, and the elimination of health disparities.

Health disparities are preventable population level differences in the burden of disease, injury, and violence and opportunities to achieve optimal health [2]. Since the 1980 Black Report's national level study of health disparities [3], there has been a heightened focus on the issues, internationally, and on the collection of explanatory data. Increasingly recognized is the impact of these disparities on the health and wellbeing of Indigenous communities across the globe and an improved understanding of what the available data can and can not reveal about health inequality [4].

In Canada for example, higher levels of chronic diseases, injuries and suicides combine to form an Indigenous life expectancy gap of 6 years or more [5]. The U.S. Indian Health Service reports major Indigenous mortality disparities for tuberculosis (450 percent higher than for the total population), diabetes mellitus (177 percent higher), poisoning (118 percent higher), homicide (86 percent higher), suicide (60 percent higher) and pneumonia and influenza (37 percent greater) [6]. Estimated life expectancy for the Australian Indigenous population in 2010-12 was 10.6 years lower for males and 9.5 years lower for females than for their non-Indigenous counterparts [7]. Maori life expectancy in 2012-14 was 7.1 years lower than for non-Maori for both sexes combined [8]. The New Zealand Medical Association reported "In New Zealand, Māori have poorer health than nonMāori across many measures, including heart disease, cancer and mortality. This persists when other factors such as socioeconomic status and smoking have been controlled for. Explanations for this are multifactorial" [9].

\section{Creation of a multinational interest group}

Discussions between health data professionals from the United States and Australia in 2004 quickly grew to form a group of like-minded individuals from Australia, Canada, New Zealand and the United States. We decided that organizing our first meeting as a satellite to a larger Indigenous meeting would help with identifying additional members and facilitate travel plans for our Indigenous members. We identified the 2005 meeting of another Indigenous professional organization, the International Network for Indigenous Health Knowledge and Development (INIHKD) as a possible candidate and entered into discussions with the Canadian INIHKD hosts. The INIHKD, founded in 2001, brings together Indigenous health professionals, researchers and health providers from several countries to promote the development of Indigenous and community-led research, health services and workforce development and creates opportunities for countries to share approaches, experiences and results for the improvement of health care systems for Indigenous people. When we explained the statistical interests of our group, the INIHKD organizers recognized the potential value of our proposed presentations to their members and agreed to include two sessions of presentations by our group within the INIHKD meeting. We followed that with a separate organizing meeting as the first official meeting of the IGIHM. The organizing meeting produced the guiding principles for the group and a plan of action that included regular communications, linkages to other groups and identifying sources of potential funding and support.

Perhaps the key element of the group's development was to connect people and ideas with a focus on what was to become the unifying principle of the group - the right of Indigenous peoples to count and be counted. Our Terms of Reference document further identified our vision - To improve, internationally, the availability, quality, depth, and utility of health knowledge and data for Indigenous populations - and our commitment - To promote effective dialog across countries, populations, and agencies in order to ensure that Indigenous populations have rights to all their data, can expect accurate data, and can contribute to strengthening data collection, analysis, and interpretation at all levels.

\subsection{Who we are and how we work together}

The goals of the IGIHM are: 1) build multinational partnerships; 2) develop and promote/increase improved methods; and 3) inform policy. Partnerships promote coordinated and collaborative efforts across countries through facilitated dialog on cross-cutting is- 
sues of import to all member countries. The promotion and increase of improved methods involve developing criteria to ensure data quality and health data, which are both useful and meaningful for Indigenous lives. A process for information sharing and inclusion of culture, history and Indigenous worldviews are essential to improving the collection, interpretation, use and dissemination of health data. In order to transform current data policies and practices, national statistical agencies and others need to be informed of the problems and potential solutions. Community and tribal organizations must be part of the dialog and collaborative projects to inform policy development locally and globally.

Group membership originated with participation from the four countries with Indigenous populations and well-developed statistical systems. An important focus of the group has always been to invite additional countries to participate. Representation from participating countries includes Indigenous and nonIndigenous statistical and health experts, decisionmakers, researchers, and health professionals, plus representatives of national and world health and statistical agencies, and others. Membership, while fluid, has since evolved to include additional countries (Brazil, Sweden). Group co-chairs facilitate interactions and activities through monthly calls and a rotation of biennial meetings among the four countries. Topical subgroups and writing teams develop thematic areas of focus such as mortality measurement and publications in mainstream journals such as The Lancet and the Statistical Journal of the IAOS.

\subsection{Development of the group in each country}

Each participating country contributes membership and participates in its own way.

In Australia, members have been drawn largely but not entirely from the National Advisory Group on Aboriginal and Torres Strait Islanders Health Information and Data (NAGATSIHID), with members from Indigenous organizations such as the National Aboriginal Community Controlled Organization, Indigenous academics, and statistical and government agencies involved in health measurement as well as experts in the field of measurement.

In the United States, the initial nucleus of members reached out to various organizations, including the Indian Health Service, universities, and state and other government organizations, to identify like-minded individuals. US participants have varied over time but have always included Indigenous researchers and rep- resentatives from the Indian Health Service, from various parts of the Centers for Disease Control and Prevention and other government agencies, and from academia.

In Canada, participation in the IGIHM has come from academics, government agencies and Indigenous organizations; both Indigenous and non-Indigenous people have participated in IGIHM activities. The topics of interest are those in common with the other countries, particularly infant and child mortality and identification of Indigenous people in health data. Data linkage methodologies are of special interest to Canadian participants because of the jurisdictional complexity of the health system, multiple Indigenous groups, and issues of data ownership and possession.

For New Zealand, most of the initial membership was identified during the first planning meeting in 2005. Members share an interest in data linkage, given New Zealand's pioneering work to improve the measurement of Maori mortality and life expectancy. New Zealand members also made important contributions to the development of the organizational principles of the group.

\section{IGIHM accomplishments and activities to date}

Since its founding in 2005, the IGIHM has pursued a variety of activities centered on multi-national partnerships, as well as the promotion of improved methods for the collection, analysis, interpretation and dissemination of information useful for improving the health of Indigenous populations and enhancing Indigenous health knowledge and data. The group is committed to the promotion of effective dialog across countries, populations, and agencies in order to ensure that Indigenous populations have rights to all data, can expect accurate data, and can contribute to strengthening data collection, analysis, and interpretation at all levels.

In addition to published reports of international meetings and workshops sponsored by the IGIHM, group members have authored or co-authored a variety of articles on various data topics in academic journals as well as newspaper articles. Key topics include: Best practice for estimation of Indigenous mortality [10,11], Indigenous data linkage [12], the need for international efforts to improve statistics on Indigenous peoples $[13,14]$, improving Indigenous statistics in Canada [15], and Indigenous identification. Members also have served on various committees concerning Indigenous data quality and availability in each of our countries. 
In recent years, the topic of Indigenous wellness has become important to the work of the group. IGIHM held a special symposium in Vancouver in October 2014 to explore Indigenous perspectives on wellness [16]. Wellness is that extra element that is missing in most Western conceptualizations of health. Although it is common to Indigenous peoples, it is not universally the same and is hard to define. Nevertheless, the goals of wellness measurement are to use it in clinical practice, and in monitoring progress in health interventions and health programming.

\section{Ongoing challenges for Indigenous health measurement}

An important statistical problem shared by the four countries is misidentification of the Indigenous population on administrative and health records. Misclassification may result from several factors, from misclassification of decedents by hospital staff and funeral directors to respondent reluctance to report Indigenous status. Indigenous misclassification has been studied extensively in the United States, for example documenting under-reporting of Indigenous status on death and cancer records resulting in significant underestimates of Indigenous death rates and cancer prevalence [17]. In Australia, numerous studies have documented Indigenous misclassification on hospital and death records [18-20].

It has been recognized however, that improved identification alone will not necessarily drive improvement and, for that purpose, a focus on the measurement of services is required. Accordingly, a framework for measurement of Indigenous services has now been developed by IGIHM members for consideration and use by both Indigenous and mainstream agencies and communities involved with the development and conduct of service delivery.

Collecting survey data on Indigenous health has its own difficulties, as the small relative size of the Indigenous population in three of the four countries (Australia: 3.0 percent; Canada: 4.9 percent; USA: 1.7 percent) and its dispersion presents challenges for efficient sample design, although Australia has an extensive national survey program for Indigenous health and social statistics. Some alternatives exist, for example the Contract Health Service Delivery Area (CHSDA) counties in the USA, in which 64 percent of the American Indian/Alaska Native population live. Higher levels of homelessness or residential instability in remote areas are obstacles to complete census coverage of the Indigenous population. In New Zealand the collection of health data and related survey data, census information and administrative data has policy in place to standardize its collection [21,22].

In addition, three of our four countries face basic challenges of data availability. In Australia, Indigenous data on some topics are routinely published only for selected states and territories: those with sufficient numbers of known Indigenous residents and with satisfactory levels of Indigenous identification. In Canada, national data on the Indigenous populations are limited to the recently restored census long form (covering onefifth of the population) [23] and to tax records that can be linked to other administrative records [24]. In the United States, the best health data on the Indigenous population are from the Indian Health Service. This information is limited however to the estimated 64 percent of the American Indian and Alaska Native population served by the Indian Health Service [17,25]. The Maori of New Zealand on the other hand represent about 15 percent of the total population and have available relatively abundant data from national censuses and surveys as well as administrative records.

National efforts to improve Indigenous data quality often have not been successful despite a promising beginning. For example, the National Advisory Group on Aboriginal and Torres Strait Islanders Health Information and Data (NAGATSIHID) was founded to address concerns about Indigenous data in Australia. NAGATSIHID was the principal committee responsible for providing broad strategic advice on ways to improve the quality and availability of data and information on Aboriginal and Torres Strait Islander health and health service delivery. The committee brought together a range of Indigenous health information management activities into a coordinated and strategic process. NAGATSIHID was recently abolished as an incidental component of a rationalization of government committees.

There is an urgent need to build on the momentum of countries that are willing and able to address these disparities and data challenges to ensure that programs, services, and policies are built on accurate and reliable data. Currently, the United States is unable to produce an accurate measure of life expectancy for their Indigenous population, owing to misclassification of Indigenous status on death records. Similar problems exist in Canada and there are ongoing efforts in Australia to try to deal with misclassification on death records. Accurate measurement of health disparities is impos- 
sible without accurate data, just as is measurement of progress in addressing these disparities. Obtaining grants to address health problems usually calls for data to document need; justifying health spending calls for accurate measurement of need. These and many other data needs call out for improvement in the availability of Indigenous health data.

\section{Related efforts}

There have been multiple efforts to identify and resolve Indigenous health and related issues with varying degrees of success. The United Nations Declaration on the Rights of Indigenous Peoples [26] was adopted by 143 countries in 2007, and interestingly, voted against by Australia, Canada, New Zealand, and the United States. Since that time, however, all four countries have announced support for the Declaration [27]. Other efforts include Indigenous non-governmental groups and organizations (INGO), individual country governmental efforts and even several international and multinational governmental efforts. Individual countries have established ambitious programs to address Indigenous health disparities, and in the process to improve required data collection.

In 2008, Australian state governments agreed to work together to achieve equality in health and life expectancy between Aboriginal and Torres Strait Islander people and non-Indigenous Australians by the year 2030. The Council of Australian Governments (COAG) implemented the Closing the Gap strategy, setting six ambitious targets across the areas of health, education and employment to drive progress. The strategy recognized that closing the gap in Indigenous disadvantage would require long-term, generational commitment, with effort to be directed across a range of priority areas: early childhood, schooling, health, economic participation, healthy homes, safe communities and governance and leadership. The approach was designed to be holistic, with the building blocks fitting together through the integration of policy ideas and implementation strategies. Progress to date however has been mixed and often disappointing [28].

In Canada, Pathways to Health Equity for Aboriginal Peoples is a program developed by the Canadian Institutes of Health Research to understand, implement and scale up good practice models of reducing Indigenous health inequities in four exemplar areas, namely diabetes, suicide, tuberculosis and oral health [29]. In New Zealand, the Health Research Council has sup- ported the training of Indigenous scholars and medical schools have supported entry of Indigenous students in medicine and the health sciences. This has seen an increase in the numbers of doctors and allied health professionals graduating in the last ten years.

The United States has created agencies such as the National Institute of Minority Health and Health Disparities (NIMHD formerly NCMHD), initiatives such as Healthy People including specific targets for the Indigenous population, policy including amendments to the Indian Health Care Improvement Act, and reports such as the US Commission on Civil Rights report Broken Promises: Evaluating the Native American health care system [30]. However, most of these activities are not only dependent upon the political nature of federal funding but often cannot effectively address the underlying lack of accurate statistical data that define these disparities [31].

Multinational efforts between the four countries include several agreements for collaboration between nations. In 2002, the Canadian Institutes of Health Research (CIHR), the National Health and Medical Research Council of Australia (NHMRC), and the Health Research Council of New Zealand (HRC) established a tripartite collaboration to support research in the area of Indigenous peoples' health (International Collaborative Indigenous Health Research Partnership (ICIHRP) on resilience, 2005). The CA-AU-NZ tripartite collaboration has recently been extended for a third time [32]. A 2007 memorandum of understanding (MOU) between the Department of Health and Human Services in the United States and Health Canada focuses on improving health-care delivery and access to the Indigenous populations of the two countries (HHS and Health Canada MOU 2007). These collaborations include some efforts to improve the measurement of Indigenous health status and a commitment to share improved measurement techniques.

\section{Conclusion and way forward}

There is still a great deal that needs to happen for truly representative Indigenous health data to be collected and well used. As noted above, a major issue in all four countries is the problem of identification - who is considered Indigenous and how is this documented in local, regional, and national health data? The specific issues vary somewhat by country but the problems of underestimation and misidentification, are primary challenges. Statistical tools such as data linkage are 
helping to increase the accuracy of some existing data, but statistical and ethical challenges for ongoing data collection continue. Even where data exist and deemed somewhat reliable, small sample sizes hinder their use. Indigenous data, particularly at national levels, may be excluded from reports or be accompanied by interpretation warnings.

The IGIHM is attempting to address these challenges through sharing of best practices, lobbying national statistical organizations, and reaching out to countries beyond the four founding members of the group. The release of this special issue of the Journal of the International Association for Official Statistics marks another step in the IGIHM journey, bringing our message of the need for better data for the Indigenous to the international statistical community. We hope that this will increase the awareness within national statistical organizations of the need to improve data and measurement methods, to better describe and help improve the health status of their Indigenous populations.

\section{Acknowledgments}

The authors offer their sincere and profound thanks to Dr. Sam Notzon, Director, International Statistics Program, National Center for Health Statistics, at Centers for Disease Control and Prevention, for his part in creating the International Group for Indigenous Health Measurement (IGIHM) and for his unwavering support and contributions to the work of this group including his help in drafting this paper. We also thank our friends and colleagues across the globe who are part of the IGIHM.

\section{References}

[1] Australian Institute of Health and Welfare (AIHW) 2006. International Group for Indigenous Health Measurement, Vancouver 2005. Cat. no. IHW 18. Canberra: AIHW.

[2] National Research Council, Perrin E, Ver Ploeg M. Eliminating health disparities: Measurement and data needs. National Academies Press; 2004.

[3] Black SD. Inequalities in health: the Black report; 1980.

[4] Anderson I, Robson B, Connolly M, Al-Yaman F, Bjertness E, King A, Tynan M, Madden R, Bang A, Coimbra Jr CE, Pesantes MA. Indigenous and tribal peoples' health (The Lancet - Lowitja Institute Global Collaboration): a population study. The Lancet. 2016 Jul 9; 388(10040): 131-57.

[5] Canada. Health Canada. A statistical profile on the health of First Nations in Canada. Health Canada; 2003.

[6] Indian Health Service, 2015. Trends in Indian Health, 2014 Edition.
[7] Heuvel AV. The Health and Welfare of Australia's Aboriginal and Torres Strait Islander Peoples, 2015. Australian Institute of Health and Welfare; 2015.

[8] Statistics New Zealand 2015. New Zealand Period Life Tables 2012-14.

[9] New Zealand Medical Association. Health equity position statement. The New Zealand Medical Journal (Online). 2011 Mar 4; 124(1330)

[10] Coleman C, Elias B, Lee V, Smylie J, Waldon J, Hodge FS, Ring I. International Group for Indigenous Health Measurement: Recommendations for best practice for estimation of Indigenous mortality. Statistical Journal of the IAOS. 2016 Jan 1; 32(4): 729-38.

[11] Freemantle J, Ring I, Arambula Solomon TG, Gachupin FC, Smylie J, Cutler TL, Waldon JA. Indigenous mortality (revealed): the invisible illuminated. American Journal of Public Health. 2015 Apr; 105(4): 644-52.

[12] IGIHM 2013. Indigenous Linkage Workshop, Montreal Monday 5th August 2013 - Related papers.

[13] Australian Institute of Health and Welfare (AIHW) 2009. International Group for Indigenous Health Measurement, 2006 Canberra

[14] Madden R, Axelsson P, Kukutai T, Griffiths K, Storm Mienna C, Brown N, Coleman C, Ring I. Statistics on indigenous peoples: International effort needed. Statistical Journal of the IAOS. 2016 Jan 1; 32(1): 37-41.

[15] Smylie J, Firestone M. Back to the basics: Identifying and addressing underlying challenges in achieving high quality and relevant health statistics for indigenous populations in Canada. Statistical Journal of the IAOS. 2015 Jan 1; 31(1): 67-87.

[16] Macklin C, Beaudoin E, Lu K, King M, King A. A Synthesis: Indigenous Wellness Indicators Day. IAPH-FNHA-IGIHM Conference Report, 25pp.

[17] Jim MA, Arias E, Seneca DS, Hoopes MJ, Jim CC, Johnson NJ, Wiggins CL. Racial misclassification of American Indians and Alaska Natives by Indian Health Service contract health service delivery area. American Journal of Public Health. 2014 Jun; 104(S3): S295-302.

[18] Jackson Pulver LR, Bush A, Ward J. Identification of Aboriginal and Torres Strait Islander women using an urban obstetric hospital. Australian Health Review. 2003; 26(2): 19-25.

[19] Australian Institute of Health and Welfare 2013. Report on the use of linked data relating to Aboriginal and Torres Strait Islander people.

[20] Neville SE, Taylor LK, Moore H, Madden R, Ring I, Jackson Pulver LR, Tickle L. Using linkage between hospital and ABS mortality data to enhance reporting of deaths among Aboriginal and Torres Strait Islander peoples. Australian and New Zealand Journal of Public Health. 2011 Dec; 35(6): 543-8.

[21] Ministry of Health. Ethnicity data protocols for the health and disability sector. Wellington, New Zealand: Ministry of Health. 2004 Dec 1.

[22] Statistics New Zealand. Understanding and working with ethnicity data. Statistics New Zealand. 2005 Apr.

[23] Statistics Canada 2015. Mandatory long-form census.

[24] Tjepkema M, Wilkins R, Senécal S, Guimond É, Penney C. Mortality of Métis and registered Indian adults in Canada: an 11-year follow-up study. Health Reports. 2009 Dec 1; 20(4): 31.

[25] Anderson RN, Copeland G, Hayes JM. Linkages to improve mortality data for American Indians and Alaska Natives: a new model for death reporting? American Journal of Public Health. 2014 Jun; 104(S3): S258-62. 
[26] Assembly UG. United Nations Declaration on the Rights of Indigenous Peoples; 2007.

[27] Assembly UG. United Nations Declaration on the Rights of Indigenous Peoples; 2017.

[28] Turnbull M. Closing the Gap: Prime Minister's Report 2018. Department of Prime Minister and Cabinet; 2018.

[29] Canadian Institutes of Health Research. 2012. Pathways to Health Equity for Aboriginal Peoples.

[30] Berry M, Reynoso C, Braceras J, Edley C, Kirsanow P, Meeks E, Redenbaugh R, Thernstrom A. Broken promises: Evaluating the Native American health care system. US Commission on Civil Rights, Office of the General Counsel. 2004.
[31] World Health Organization. World Health Report (2010) Background Paper No. 33. Jackson Pulver LR, Haswell MR, RI, et al. Indigenous Health - Australia, Canada, Aotearoa New Zealand, and the United States - Laying claim to a future that embraces health for us all.

[32] Canadian Institutes of Health Research. International collaboration to improve the health and wellness of Indigenous peoples through research 2017. 